\title{
APROPRIAÇÃO DE IMÓVEIS ABANDONADOS COMO INSTRUMENTO DE PLANEJAMENTO NOS PLANOS DIRETORES URBANOS E DE EFICIÊNCIA NO USO DE RECURSOS PÚBLICOS
}

\author{
APPROPRIATION OF ABANDONED PROPERTIES AS A PLANNING TOOL IN URBAN MASTER PLANS \\ AND EFFICIENCY IN THE USE OF PUBLIC RESOURCES
}

\section{Sérgio Alexandre de Moraes Braga Junior ${ }^{1}$ Illana Cristina Dantas Gomes ${ }^{2}$}

\section{RESUMO}

O objetivo do artigo é analisar a apropriação de imóveis abandonados à luz da função social da propriedade urbana, a sua destinação para fins de interesse público ou social, nos termos expostos no artigo 1.276 do Código Civil, e a sua incorporação como instrumento de planejamento nos Planos Diretores Urbanos. Verificou-se, a partir de pesquisa qualitativa e quantitativa e método de abordagem dialético-dedutivo, dados oficiais quanto ao déficit de moradia e o número de imóveis abandonados no Brasil, e a existência de instrumento e procedimento próprios nos Planos Diretores Urbanos das capitais brasileiras. Como resultados, apenas as capitais São Paulo/SP e Vitória/ES possuíam instrumento próprio, com a devida regulamentação, legitimando o poder público municipal a se apropriar desses imóveis. Conclui-se que a apropriação de imóveis abandonados possa aumentar a eficiência no uso de recursos públicos com habitação social, aluguel social, imóveis para prestação de serviços públicos e como instrumento preferencial ao direito de preempção em imóveis com valor histórico, esperando-se que nas revisões dos Planos Diretores municipais o instrumento seja incorporado, em razão do procedimento previsto na Lei Federal № 13.465/2017.

Palavras-chave: Imóveis Abandonados. Função Social da Propriedade. Déficit habitacional. Bens vagos. Uso de recursos públicos.

\footnotetext{
${ }^{1}$ Professor Doutor dos cursos de Direito da UERN e UFRN, vinculado ao Programa de Pós-Graduação em Direito da UFRN. Afilição:Universidade Federal do Rio Grande do Norte Lattes http://lattes.cnpq.br/842943698140685 7 E-mail:salexandre.prof@gmail.com

${ }^{2}$ Advogada, Especialista em Gestão Ambiental Urbana, Especialista em Direito Civil, Mestranda em Direito pela UFRN, na área de Constituição e Garantia de Direitos, Linha 1 - Constituição, Regulação Econômica e Desenvolvimento. Afilição:Universidade Federal do Rio Grande do Norte Lattes: http://lattes.cnpq.br /2855963831644729 ORCID: https://orcid.org/0000-0002-2770-9250 E-mail:illana_cristina@yahoo.com.br
} 


\section{ABSTRACT}

The aim of this article is to analyze the appropriation of abandoned properties according to social function of urban property and the destination of these properties for public or social interest, on the terms set out in article 1,276 of the Civil Code and its incorporation as a planning tool in the Urban Master Plans. Based on qualitative and quantitative research and a dialectical-deductive approach method, official data of housing déficit and abandoned properties in Brazil and the existence of their own instrument and procedure in the Urban Master Plans of Brazilian capitals. As a result, only the capitals São Paulo/SP and Vitória/ES had their own instrument, legitimizing the municipal government to appropriate these properties. It is concluded that the appropriation of abandoned properties can increase efficiency in the use of public resources with social housing, social rent, real estate for the provision of public services and as a preferred instrument for the preemption right in properties with historical value, it is expected that in the revisions of the municipal Master Plans the instrument will be incorporated, due to the publication of Federal Law no 13.465/2017.

Keywords: Abandoned properties. Social function of property. Housing déficit. Vacant assets. Use of public resources.

\section{INTRODUÇÃO}

Uma das grandes demandas de fiscalização ambiental e urbanística que Municípios brasileiros enfrentam são os prejuízos causados por imóveis urbanos abandonados. A má conservação desses imóveis ameaçam a segurança e salubridade da edificação e é meio propício para surgimento de pragas e de vetores de doenças, além dos próprios riscos à segurança pública. Ademais, estes imóveis geralmente estão situados em bairros dotados de infraestrutura adequada, tais como rede de abastecimento de água, esgotamento sanitário, coleta de lixo, iluminação pública, ruas pavimentadas, e a sua falta de utilização torna-se um ônus para o Município, que necessita levar infraestrutura para áreas cada vez mais remotas.

A definição de imóveis subutilizados, não utilizados (incluindo abandonados) nas legislações municipais mostra-se de grande importância para fins de adoção de medidas coercitivas para utilização compulsória. Em que pese existir déficit habitacional nos grandes centros urbanos, os imóveis abandonados podem ser enquadrados como verdadeiros vazios urbanos em áreas privilegiadas. A arrecadação de tais imóveis ao ente municipal e a posterior destinação para fins de interesse social cumpriria com os preceitos da função social da propriedade urbana e da cidade. Para 
tanto, é necessário que o Município institua legalmente o procedimento para incorporá-los ao seu patrimônio.

Nesse sentido, o presente estudo busca averiguar a arrecadação de imóveis urbanos abandonados à lume da função social da propriedade urbana e da cidade e a destinação desses imóveis para fins de interesse social, particularmente pela carência de estudos com a referida temática que, de um ponto de vista de eficiência administrativa, é de grande relevância para a Administração Pública Municipal.

Os métodos utilizados para a operacionalização do trabalho foram a pesquisa bibliográfica e documental, com a análise da legislação vigente e dos referenciais teóricos do direito, além das informações colhidas nos sítios eletrônicos oficiais governamentais e das capitais dos estados brasileiros, como universo da amostra, a fim de averiguar a presença de procedimento próprio para arrecadação de imóveis abandonados no conteúdo dos seus Planos Diretores Urbanos.

Trata-se, portanto, de pesquisa quantitativa e qualitativa, com análise de conteúdo, considerando as fontes de pesquisa e os procedimentos utilizados, com método de abordagem dialético-dedutivo, em razão de análise constantes na legislação nacional, municipal, dados oficiais e doutrina jurídica.

\section{A FUNÇÃO SOCIAL DA PROPRIEDADE URBANA}

A definição de direito de propriedade sofreu várias modificações ao longo da história da humanidade, assumindo diferentes formas, de acordo com os princípios regentes em cada fase (CAMPOS, 2001), sendo a sua proteção e função objeto de disputas ideológicas (GAIO, 2000).

Nesse sentido:

Não existe um conceito inflexível do direito de propriedade. Muito erra o profissional que põe os olhos no direito positivo e supõe que os lineamentos legais do instituto constituem a cristalização dos princípios em termos permanentes, ou que o estágio atual da propriedade é a derradeira, definitiva fase de seu desenvolvimento. Ao revés, evolve sempre, modifica-se ao sabor das injunções econômicas, políticas, sociais e religiosas. Nem se pode falar, a rigor, que a estrutura jurídica da propriedade, tal como se reflete em nosso Código, é a determinação de sua realidade sociológica, pois que aos nossos olhos e sem que alguém possa impedi-lo, ela está passando por transformações tão substanciais quanto aquelas que caracterizaram a criação da propriedade individual, ou que inspiraram a sua concepção feudal (PEREIRA, 2017).

A configuração do instituto da propriedade sofre influência direta dos "regimes políticos em cujos sistemas jurídicos é concebida", de modo a não existir na história do direito um conceito único para a propriedade" (GONÇALVES, 2017, p. 240-241). Assim, admite-se que o conceito de 
propriedade deve ser dinâmico, portanto "deve-se reconhecer, nesse passo, que a garantia constitucional da propriedade está submetida a um intenso processo de relativização, sendo interpretada, fundamentalmente, de acordo com parâmetros fixados pela legislação ordinária" (GONÇALVES, 2017).

A origem histórica do nosso instituto da propriedade remonta ao Direito Romano, onde preponderava um regime individualista (PEREIRA, 2017), dispondo cada coisa de apenas um dono, a quem era conferido os mais amplos poderes, consubstanciados no usar, gozar e dispor do bem (CAMPOS, 2001).

Com base nessas características, nos séculos XIX e XX, na definição de propriedade então vigente, o proprietário tinha o direito de exercer sobre o bem, com exclusividade, o uso, a fruição, a disposição e a reivindicação (FIUZA, 2003).

Um conceito moderno seria "a situação jurídica consistente em uma relação dinâmica entre a pessoa, o dono, e a coletividade, em virtude do qual são assegurados os direitos de usar, fruir, dispor e reivindicar um bem, respeitados os direitos da coletividade" (FIUZA, 2003).

Buscando definir o conteúdo do instituto da propriedade na atualidade, leciona-se que:

A verdade é que a propriedade individual vigente em nossos dias, exprimindose embora em termos clássicos e usando a mesma terminologia, não conserva todavia conteúdo idêntico ao de suas origens históricas. E certo que só reconhece ao dominus o poder sobre a coisa; é exato que o domínio enfeixa os mesmos atributos originários - ius utendi, fruendi et abutendi. Mas é inegável também que essas faculdades suportam evidentes restrições legais, tão frequentes e severas, que se vislumbra a criação de novas noções. São restrições e limitações tendentes a coibir abusos e tendo em vista impedir que o exercício do direito de propriedade se transforme em instrumento de dominação. Tal tendência ora se diz "humanização" da propriedade, ora se considera filiada a uma corrente mais ampla com o nome do "paternalismo" do direito moderno (Colin e Capitant), ora se entende informada a nova noção pelos princípios do "relativismo" do direito (Josserand). Outros acreditam que ai se instaura uma tendência "à socialização" do direito ou socialização da propriedade, mas sem razão, porque a propriedade socializada tem características próprias e inconfundíveis com um regime em que o legislador imprime certas restrições à utilização das coisas em benefício do bem comum, sem contudo atingir a essência do direito subjetivo, nem subverter a ordem social e a ordem econômica (PEREIRA, 2017).

O autor ainda complementa acerca do crescimento dos processos expropriatórios da propriedade, tendo em vista a sua adequação à utilidade pública e ao interesse social, de forma que a utilização da propriedade está condicionada à conciliação entre as faculdades do dono e do interesse do maior número (PEREIRA, 2017). 
A propriedade, embora seja a ela atribuída a "função de ser a livre expressão e desenvolvimento da personalidade humana ou sendo a ela condicionada uma obrigação positiva", desde os tempos dos Romanos sofreu algum tipo de limitação (GAIO, 2000).

No Brasil, a intervenção da propriedade foi muito limitada até 1930, sendo, à época, o principal instrumento a desapropriação. A partir desse marco, visando submeter o direito de propriedade às exigências do interesse público, com a promulgação do Código de Águas, o Código de Minas e o Código de Florestas, em 1934, as jazidas tornaram-se de domínio público, bem como surgiu a servidão administrativa para as margens dos rios e a obrigação de preservar as florestas (GAIO, 2000).

A partir da Constituição Federal de 1988, considerando o modelo existente de sociedade contemporânea, modificou-se a regulamentação privatista prevista no Código Civil de 1916 ao atribuir à propriedade, nas suas mais diversas concepções, seja rural, urbana, empresarial, intelectual, uma função social.

Embora sob a égide da Constituição de 1988, o Código Civil de 2002, apesar de prever que o exercício da propriedade deveria estar em consonância com as finalidades econômicas e sociais, reproduziu os termos do Código de 1916, quando prevê, em seu artigo 1.228, que "o proprietário tem a faculdade de usar, gozar e dispor da coisa, e o direito de reavê-la do poder de quem quer que injustamente a possua ou detenha".

Diante do aparente conflito entre a legislação e os dispositivos constitucionais, preceitua-se que, no que tange ao direito de propriedade, ao Código Civil "cabe regular as relações civis decorrentes do direito de propriedade (como aquisição, alienação), não seu regime jurídico", o qual deverá estar fundamentado nas normas constitucionais (BORGES, 1998).

Assim, a propriedade passou a ser vista como um direito que se presta às necessidades do ser humano, embora, em seu conteúdo:

(...) não Ihe garanta a satisfação plena, uma vez que, na mesma via em que se tem o exercício do direito, caminha paralelamente um conjunto de deveres impostos ao proprietário, em razão do interesse do grupo social e da coletividade a ser resguardado (RODRIGUES, 2011).

Isso porque embora a propriedade seja um direito fundamental, recai sobre esta deveres fundamentais, sendo dever do titular exercer seu direito de forma solidária, levando em consideração os interesses da sociedade. "O exercício do direito conforme as exigências de sua função social constitui um dever fundamental, que se manifesta na própria configuração estrutural do direito de propriedade" (DIMOULIS e MARTINS, 2012). 
Há, ainda, o entendimento de que a função social não se trata de um dever fundamental, mas de um limite constitucional de natureza especial por impor ao legislador o dever de concretizála, observando o princípio da ordem constitucional econômica. Seria, portanto, uma reserva legal sui generis, por envolver "os mais diversos bens jurídicos sociais, todos, no entanto, como elementos concretizadores do princípio do Estado social lastreado nos arts. 29, III, e 170, III, da CF" (DIMOULIS e MARTINS, 2012). Complementa que:

Trata-se de um exame de proporcionalidade altamente complexo, sobretudo em razão do limite mínimo da intervenção, que não é racionalmente traçável, devendo ficar a cargo do prognóstico político-legislativo. Mas essa complexidade e relativa falência dogmática é preferível a confiar na solidariedade ou "bondade" do titular do direito à propriedade (DIMOULIS e MARTINS, 2012, p. 65).

Embora não haja consenso se a função social se trata de dever fundamental ou limite constitucional, o ordenamento jurídico pátrio adota como critério o dever de atender à sua função social para garantia constitucional do direito de propriedade (RODRIGUES, 2011). Por esse ponto, fundamentam as limitações ao direito de propriedade ocasionadas pela intervenção estatal, no interesse social e do bem público, sustentando, ainda, que o uso da propriedade deve estar relacionado com o bem da coletividade (CAMPOS, 2001).

Conforme o exposto até aqui, pode-se dizer que "a função social pode se confundir com o próprio conceito de propriedade, diante de um caráter inafastável de acompanhamento. Assim, a propriedade deve sempre atender aos interesses sociais, ao que almeja o bem comum" (TARTUCE, 2020).

Nessa linha, no que diz respeito ao bem comum, a função social da propriedade está diretamente ligada à definição objetiva desse bem, conjuntamente com o princípio da proporcionalidade, sendo ambos limitadores e moderadores de sua aplicação (REBOUÇAS, 2011).

Como elemento norteador da aplicação da função social ao direito privado e aos direitos difusos, o conceito de bem comum deve ser avaliado por cinco critérios:

(a) Finalidade no sentido aristotélico (qual o fim ou objetivo da coisa); (b) Bondade (bondade é aquilo que a todos apetece); (c) Participação (o bem é difusivo porque atua como causa final que exerce atração para que outros participem da sua bondade); (d) Comunidade ("A participação implica uma comunidade entre os participantes em função do participado"), [...] e (e) Ordem - uma comunidade não é um aglomerado de pessoas, mas um todo orgânico, com uma ordem entre as partes, onde deve imperar a harmonia e concórdia (REBOUÇAS, 2011). 
Particularmente, no artigo 186 da Constituição Federal, que trata da propriedade rural ou agrária, existem parâmetros que orientam o atendimento dessa função social da propriedade, os quais também podem ser utilizados para a propriedade urbana. São eles:

a) Aproveitamento racional e adequado da propriedade; b) Utilização adequada dos recursos naturais disponíveis e preservação do meio ambiente; c) Observância das disposições que regulam as relações de trabalho; d) Exploração que favoreça o bem-estar dos proprietários e dos trabalhadores (TARTUCE, 2020).

Em termos práticos, há concretização da função social quando, em consonância com as normas existentes, verifica-se a coincidência da atuação do proprietário com o interesse social. 0 bem, portanto, deve estar apto "para produzir sua utilidade específica, ou, pelo menos, que seu uso não se faça em desacordo com a utilidade social" (GAIO, 2000).

Assim, existe uma "necessidade de que o uso da propriedade responda a uma plena utilização, otimizando-se ou tendendo-se a otimizar os recursos disponíveis em mãos dos proprietários", ou ainda, de outro pórtico, "impõem-se que as propriedades em geral não possam ser usadas, gozadas ou suscetíveis de disposição, em contradita com estes mesmos propósitos de proveito coletivo" (GAIO, 2000).

Coadunando com essa posição, "compete ao titular de direito sobre o bem praticar atos que garantam a sua boa e efetiva exploração e não apenas a sua incorporação ao patrimônio próprio". Considerando que a ordem econômica exige o atendimento à função social pela propriedade, presume-se, então, que "o proprietário fica obrigado a explorá-la, a fazer com que seja utilizada como forma de desenvolvimento da coletividade e não apenas como forma de satisfação pessoal e individual" (RODRIGUES, 2011).

Por fim, o substabelecimento do conceito de direito subjetivo puro do direito de propriedade, com o poder de agir do titular e a defesa erga omnes, e o aparecimento de uma "relação jurídica entre pessoa, coisa e demais membros do grupo social que, embora não sejam titulares do mesmo direito ou identificáveis na relação, nela se interessam", determinam ao titular condutas em relação ao bem que ultrapassam seus interesses individuais e passam a ter caráter difuso (RODRIGUES, 2011).

Em consonância com a Constituição Federal, o Código Civil (Lei 10.406/2002) limitou o uso da propriedade imobiliária, "para impedir do proprietário atos de abuso ou a prática dos denominados atos emulativos, bem como para obrigá-lo a se utilizar de seu bem em razão do interesse coletivo e não do individual" (RODRIGUES, 2011, p. de internet), nos termos do art. 1.228, §§ 10 e 2으, do CC/2002, com a seguinte redação: 
Art. 1.228. (...)

$\S 1$.o 0 direito de propriedade deve ser exercido em consonância com as suas finalidades econômicas e sociais e de modo que sejam preservados, de conformidade com o estabelecido em lei especial, a flora, a fauna, as belezas naturais, o equilíbrio ecológico e o patrimônio histórico e artístico, bem como evitada a poluição do ar e das águas.

$\S$ 2.․ São defesos os atos que não trazem ao proprietário qualquer comodidade, ou utilidade, e sejam animados pela intenção de prejudicar outrem. (...)

Do extraído do texto legal, verifica-se que a propriedade privada permanece particular, em caráter exclusivo e perpétuo, mas não ilimitado, em razão de estar condicionado à sua finalidade social (RODRIGUES, 2011).

Nesse toar estão os planos urbanísticos e o consequente aumento da Administração Pública sobre a propriedade urbana, cuja definição é por eles dada, de modo que a propriedade cumpre sua função social quando está de acordo com as prescrições de ordenação da cidade, expressas no plano diretor municipal (GAIO, 2000).

A função social da propriedade urbana emerge de um pressuposto primordial de importância de que o urbanismo é uma função pública da Administração dirigente, determinando a identidade física e o consequente aproveitamento dos bens (GAIO, 2000).

Ao exposto, verifica-se que, acompanhado da garantia constitucional do direito de propriedade, está a obrigatoriedade do cumprimento da função social no uso do bem imóvel, particularmente por a propriedade ser um dos componentes da atividade econômica e que não pode ser explorada, ou não explorada, de forma desordenada, pelo proprietário.

\section{DO DIREITO À MORADIA E O DÉFICIT HABITACIONAL NOS MUNICÍPIOS}

A urbanização e crescimento das cidades trouxeram consigo o problema habitacional. No meio rural, a utilização de terras públicas ou particulares, ainda que não de sua propriedade, para sua própria moradia e produção de alimentos, não expunha a tal problema (SILVA, 2010). Nesse sentido, a partir da migração do homem para a cidade, passou-se a discutir acerca da existência do direito à moradia.

No que tange ao direito brasileiro, o direito à moradia foi incorporado à Constituição Federal de 1988 por meio da Emenda Constitucional 26/2000, com sua inclusão entre os direitos sociais, previstos no art. 60 .

À União coube instituir diretrizes para a habitação (art. 21, inciso XX), estatuindo a Constituição competência comum da União, dos Estados, do Distrito Federal e dos Municípios para "promover programas de construção de moradias e a melhoria das condições habitacionais e de 
saneamento básico" (art. 23, inciso IX). Tais normas objetivam a satisfação do direito à moradia a todos, inclusive aos hipossuficientes de provê-lo por seus próprios meios (SILVA, 2010).

O direito à moradia significa, prioritariamente, "não ser privado arbitrariamente de uma habitação e de conseguir uma; e, por outro lado, significa o direito de obter uma", sendo considerado um direito social complexo e multifacetado (SILVA, 2010).

Nesse toar, considera-se como piso vital mínimo para uma sadia qualidade de vida e, por conseguinte, para a dignidade da pessoa humana, em um ambiente artificial, como o são as cidades, a habitação, o trabalho, o lazer e a circulação para caracterizar os quatro elementos, nos termos da Carta de Atenas, de novembro de 1933, que compõem a função social da cidade, prevista no art. 182 da Constituição Federal de 1988.

Em contrapartida haver a garantia de tal direito na Constituição Federal, o déficit habitacional existente nos municípios brasileiros é uma realidade.

Por meio da Pesquisa Nacional por Amostra de Domicílios Contínua de 2018, constatou-se que $12,8 \%$ da população brasileira residia em domicílios com restrição de acesso às condições de moradia, levando em consideração a ausência de pelo menos uma inadequação nos domicílios a partir de quatro critérios elencados: domicílio sem banheiro de uso exclusivo; com paredes externas construídas predominantemente com materiais não duráveis; com adensamento excessivo; e com ônus excessivo de aluguel. Esse percentual equivale a 26,6 milhões de pessoas sem condições adequadas de moradia. Entre a população com renda per capita inferior a US\$ 5,50 per capita por dia, a proporção equivale a 29,3\% (IBGE, 2019).

A partir de 2016, com a mudança de metodologia da pesquisa na coleta de dados pelo IBGE, o cálculo para estimativa do déficit habitacional restou prejudicado, no entanto, em termos de número de domicílios, foi estimado que este correspondia a 6,355 milhões de domicílios, dos quais 5,572 milhões, ou 87,7\%, estavam localizados nas áreas urbanas (FJP, 2018).

Sob essa perspectiva, políticas públicas para habitação integraram o ordenamento jurídico brasileiro, tais como o Sistema Nacional de Habitação de Interesse Social (Lei n.o 11.124, de 16 de junho de 2005) e a Lei n.o 11.977, de 7 de julho de 2009, que instituiu Programa Minha Casa Minha Vida, que cria "mecanismos de incentivo à produção e aquisição de novas unidades habitacionais ou requalificação de imóveis urbanos e produção ou reforma de habitações rurais, para famílias com renda mensal de até $\mathrm{R} \$ 4.650,00^{\prime \prime}$ (art. 1ㅇ).

Embora tais medidas tenham ampliado o acesso à moradia, muitas famílias encontram-se em situação de vulnerabilidade ou miserabilidade, não possuindo meios econômicos para ingresso em programas habitacionais que exijam, ainda que em prestações módicas, contrapartida monetária. Assim, em muitos municípios, o auxílio moradia, comumente conhecido como aluguel social, é 
instituído como benefício assistencial eventual para atender à demanda urgente por moradia a famílias em situação de vulnerabilidade temporária e de calamidade pública, tendo como base legal o art. 22, da Lei n. 9 8.742, de 7 de dezembro de 1993.

Contudo, muitas vezes, o benefício, que possui caráter temporário, torna-se inviável para a necessidade permanente de habitação por famílias que não possuem condições econômicas para o seu sustento. Desse modo, ficam na dependência da existência de programas instituídos pelo poder público para distribuição de casas populares, que, em cenário de crise econômica tornam-se escassos.

Não se pode deixar de mencionar a parcela da população que, sem acesso à moradia digna, ocupa irregularmente áreas de risco - áreas suscetíveis à ocorrência de deslizamentos de grande impacto, inundações bruscas ou processos geológicos ou hidrológicos correlatos, nos termos da Lei n.. 12.608, de 10 de abril de 2012 - dentro das cidades, ocasionando problemas sociais, ambientais e de defesa civil.

Nessa perspectiva, verifica-se, pois, a relevância de criação de instrumentos concretos na legislação dos municípios, que atendam eficazmente o acesso de grupos sociais em dependência econômica à moradia digna, em uma cidade estruturada para recebê-los, buscando a organização da estrutura urbana e habitacional para abrigá-los. E, num aspecto mais amplo, não apenas acesso à moradia ou a ocupação do solo, mas também a uma estrutura de recursos de que dispõe uma cidade.

\section{DOS IMÓVEIS URBANOS SUBUTILIZADOS E NÃO UTILIZADOS}

A propriedade de bens imóveis possui, na perspectiva dos proprietários, como bem de seu interesse exclusivo, não da coletividade, possuindo status de poder e domínio econômico, em virtude da associação de riqueza acumulada à quantidade de bens adquiridos durante a vida, esperando-se que a locação de imóveis constituintes do patrimônio imobiliário individual seja uma garantia de renda fixa.

Sob esse ângulo, verifica-se que o acúmulo de riquezas por meio de bens imóveis desdobrase, muitas vezes, em um patrimônio inutilizado ou subutilizado, contra a vontade do proprietário, acarretando um ônus ao seu titular e frustrando a sua expectativa de fonte de riqueza (RODRIGUES, 2011).

A escolha, em alguns casos, é o abandono dos imóveis, gerando deterioração, para exploração econômica futura, na expectativa de ver reaquecido o mercado imobiliário, com vantajosos negócios (RODRIGUES, 2011). 
Ao tratar da política urbana, o art. 182, § 4ㅇ da Constituição Federal, estabeleceu, como uma de suas bases, os casos de solo urbano não edificado, subutilizado e não utilizado, conceitos discriminados no art. 5 do Estatuto da Cidade (Lei n. 10.257, de 10 de julho de 2001):

Art. 5o Lei municipal específica para área incluída no plano diretor poderá determinar o parcelamento, a edificação ou a utilização compulsórios do solo urbano não edificado, subutilizado ou não utilizado, devendo fixar as condições e os prazos para implementação da referida obrigação.

$\S 1^{\circ}$ Considera-se subutilizado o imóvel:

I - cujo aproveitamento seja inferior ao mínimo definido no plano diretor ou em legislação dele decorrente;

Contudo não haja distinção entre subutilização e não utilização na lei, as duas expressões não são sinônimas. Apenas restou definido que a subutilização corresponde a aproveitamento inferior ao mínimo definido na legislação, normalmente dispondo esta, a partir de índices urbanísticos, qual o coeficiente de aproveitamento ou taxa de ocupação mínimos deverá incidir no terreno para caracterizar-se como utilizado.

Doutrinariamente, a não utilização significa que o imóvel não possui qualquer tipo de uso ou de atividade, originária da passividade do proprietário. Já a subutilização corresponde ao uso indevido ou impróprio, em discordância com os padrões de uso fixados no plano diretor; oriunda de uma postura ativa do proprietário (CARVALHO FILHO, 2009).

Depreende-se da previsão legal que não basta o interesse pessoal de obter uma construção patrimonial e o acúmulo de riquezas por meio de bens imóveis, pois que com o direito de propriedade sobre imóveis nasce o dever de uma postura ativa de zelo, manutenção e destinação útil, para além de ser um sujeito passivo de obrigações tributárias. A proteção do seu bem não se consuma com a simples condição de proprietário (RODRIGUES, 2011).

A classificação exposta na lei pode ser considerada um desdobramento para averiguar o cumprimento da função social da propriedade urbana, critério dosador da garantia constitucional do direito de propriedade.

Haveria, pois, a concretização da função social quando, respeitando-se as normas existentes, a atuação do proprietário convergisse com o interesse social. Para alcançar tal fim, o bem posto em aptidão para produzir sua utilidade específica, ou, pelo menos, que seu uso não se faça em divergência com a utilidade social (GAIO, 2000).

Desta feita, o uso da propriedade responderia a uma plena utilização, bem como estaria imposto a esta não ser usada, gozada ou suscetível de disposição, em discordância com propósitos de proveito coletivo (GAIO, 2000). 
Isso porque, conforme estatui a alínea " $\mathrm{e}$ ", inciso VI, do art. 2o do Estatuto da Cidade, é diretriz da política urbana a ordenação e controle de uso do solo de forma a evitar "a retenção especulativa do solo urbano, que resulte em sua subutilização ou não utilização".

Para o cumprimento da função social dos imóveis urbanos, a própria Lei estabeleceu instrumentos, visando evitar a subutilização ou não utilização destes, tais como o parcelamento, edificação e utilização compulsórios, previsto no caput do art. 5ㅇ, o imposto sobre a propriedade predial e territorial urbana - IPTU progressivo no tempo, previsto no art. 7으, e a desapropriação com pagamento de títulos, estabelecida no art. 8ำ, como sanções sucessivas.

Isso porque, todavia a propriedade seja uma forma de a pessoa humana conquistar parte de seus anseios e de suas necessidades, estes devem estar condicionados ao atendimento dos interesses da coletividade, seja qual for a espécie de bem objeto do direito. Para o direito de propriedade ser inerente à condição do ser humano, inclusive por o direito à moradia estar relacionado à dignidade humana, deve haver efetiva utilização (RODRIGUES, 2011).

Para que a propriedade cumpra a sua função social, a forma de uso, exploração e destinação feita pelo proprietário tem que se pautar da necessidade de garantir a dignidade da pessoa humana, permitindo habitação e dignidade dentro dos centros urbanos pela ordenação das cidades e dos espaços urbanos abertos e fechados (RODRIGUES, 2011).

Sob esse ponto de vista, o direito de propriedade estará resguardado desde que atenda ao seu fim, que, embora em um primeiro momento seja de interesse privado, não pode estar em dissonância com o interesse coletivo, particularmente no caso de imóveis urbanos, quando há investimento público para guarnecer o imóvel com toda a infraestrutura urbana necessária à moradia e/ou prestação de serviços.

A partir da interpretação da norma cominada no Estatuto da Cidade, portanto, busca-se a garantia do bem-social em imóveis não aproveitados, improdutivos ou que não tenham sido explorados em todo seu potencial, conhecendo-se que a norma ainda contempla o direito constitucional à habitação e à moradia (RODRIGUES, 2011).

No Brasil, contudo a Constituição Federal de 1988 tenha estabelecido a necessidade de cumprimento da função social da propriedade e o Estatuto da Cidade, datado do ano de 2001, tenha como diretriz evitar a subutilização ou não utilização de imóveis urbanos, inclusive com a positivação de instrumentos da política urbana impondo sanções, como já mencionado, verifica-se, a partir dos dados do censo de 2009, que mais de 6.097 .778 de domicílios particulares urbanos brasileiros foram classificados como não ocupados e vagos e outros 3.933.271 de domicílios urbanos particulares encontram-se como não ocupados de uso ocasional, apontando não se tratarem de moradia fixa (SINOPSE DO CENSO DEMOGRÁFICO 2010 - IBGE, Tabela 1.16). 
Ainda, a partir de dados do Programa Nacional de Amostra de Domicílios - PNAD 2015, verificou-se que o Brasil possui 7,906 milhões de imóveis vagos, com 80,3\% deles localizados em áreas urbanas, dos quais 6,893 milhões estão em condições de serem ocupados e 1,012 milhão estão em construção ou reforma (FJP, 2018).

Os dados apontam, portanto, que os instrumentos de política urbana previstos no Estatuto da Cidade como sanção a proprietários que mantém imóveis vagos ou têm sido insuficientes como meio coercitivo, revertendo a situação inerte, ou não vêm sendo aplicados a contento pelos municípios, de modo que o número de imóveis vagos supera o déficit habitacional nas áreas urbanas, indicando que para o proprietário, ainda que sujeito a sanções, pode ser vantajoso, de um ponto de vista econômico, manter imóveis sem ocupação.

\section{DA PREVISÃO LEGAL PARA UTILIZAÇÃO COMPULSÓRIA DE IMÓVEIS URBANOS ABANDONADOS PARA FINS DE INTERESSE PÚBLICO E SOCIAL}

O acúmulo de patrimônio, particularmente de bens imóveis, ainda é associado a uma qualidade de vida sem maiores problemas financeiros, em razão da possibilidade de geração de renda, por meio dos seus frutos ou de própria venda destes. Desta maneira, a multiplicidade de imóveis concentrados no patrimônio individual ou espólio de uma pessoa pode acarretar dificuldades em sua administração ou até desconsideração do bem ante o numerário ou valor econômico dos demais bens. Ainda não se pode deixar de mencionar o proposital "esquecimento" de bens imóveis à espera da valorização imobiliária dos terrenos com o chegada da urbanização.

De fato, a existência de mais de 6 milhões de imóveis vagos e em condições de ocupação, conforme exposto no tópico anterior, e sem exploração pelos seus titulares ocasiona problemas sociais, ambientais, estéticos, de segurança pública e inerentes à má conservação da edificação, tais como depósito irregular de lixo, proliferação de vetores de doenças e danos a construções vizinhas e transeuntes.

Nessa toada, os conflitos relativos à ocupação dos imóveis urbanos decorrem de uma irregular utilização destes em relação às necessidades da população (RODRIGUES, 2011), bem como do próprio poder público, especialmente quando estes se encontram em áreas dotadas de infraestrutura urbana satisfatória, gerando maiores despesas com a manutenção de serviços urbanos para o ente federativo e consumindo recursos públicos que poderiam ser destinados à implantação de infraestrutura em áreas com urbanização mais recente.

Conforme exposto em tópico anterior, o art. 5o do Estatuto da Cidade determina que lei poderá determinar a utilização compulsória dos imóveis urbanos subutilizados ou não utilizados, 
fixando condições e prazos, em razão da necessidade de cumprimento da função social da propriedade urbana, cabendo aos proprietários a exploração do bem, podendo até ser privado deste, caso seu titular permaneça silente, deixando-o em abandono.

No que tange à matéria, estabelece o art. 1.275 do Código Civil de 2002 os casos de perda da propriedade, sendo um deles o abandono (inciso III). Complementa o art. 1.276 que o imóvel urbano abandonado poderá ser arrecadado como bem vago, podendo passar três anos depois à propriedade do Município. Vejamos:

Art. 1.276 O imóvel urbano que o proprietário abandonar, com a intenção de não mais o conservar em seu patrimônio, e que se não encontrar na posse de outrem, poderá ser arrecadado, como bem vago, e passar, três anos depois, à propriedade do Município ou à do Distrito Federal, se se achar nas respectivas circunscrições.

$\S 1$ 1․ O imóvel situado na zona rural, abandonado nas mesmas circunstâncias, poderá ser arrecadado, como bem vago, e passar, três anos depois, à propriedade da União, onde quer que ele se localize.

$\S 2$ o Presumir-se-á de modo absoluto a intenção a que se refere este artigo, quando, cessados os atos de posse, deixar o proprietário de satisfazer os ônus fiscais.

No Código Civil de 1916 havia previsão semelhante no art. 589, quando se podia arrecadar imóvel urbano como bem vago pelo Estado, passando, após 10 (dez) anos à propriedade do ente estatal. A mudança, com a entrada em vigência do Código de 2002, deu-se com o encurtamento do prazo: de 10 para 3 anos, passando a competência para a arrecadação de imóveis urbanos abandonados ao Município.

A alteração da competência do ente estadual para o ente municipal se mostrou coerente com a incorporação do conteúdo do $§ 2^{\circ}$, que estabeleceu a presunção absoluta de abandono a ausência de satisfação dos ônus fiscais por parte do proprietário. O imposto que recai sobre a propriedade urbana, IPTU, é de competência do município, conforme determina o Código Tributário Nacional e a Constituição Federal de 1988, de modo que a arrecadação de imóveis urbanos abandonados com dívidas de IPTU equivaleria à adjudicação do bem em eventual execução fiscal para cobrança dos débitos fiscais do imóvel, dispensando-se o referido processo judicial, em se configurando a situação de abandono, o que, por si, representaria uma economia processual, tanto no judiciário, quanto administrativa.

É de se destacar que não se pode confundir que os três anos que a norma determina não se trata do lapso temporal para determinação do abandono do bem imóvel, mas de prazo estabelecido para que o bem abandonado arrecadado como vago passe ao domínio do Município. Os requisitos para configuração do abandono, da ausência de atos de posse, para então se declarar como bem 
vago, deverá ser determinado pelo Município a partir de critérios próprios, sendo alguns deles elencados na Lei Federal n.ㅇ 13.465/2017.

Quanto ao tema, foi editada a Medida Provisória n.o 759/2016, convertida na Lei $13.465 / 2017$, detalhando, em seu art. 64 , o procedimento administrativo a ser adotado por parte dos municípios e Distrito Federal para arrecadação de imóveis abandonados, nos seguintes termos:

Art. 64. Os imóveis urbanos privados abandonados cujos proprietários não possuam a intenção de conservá-los em seu patrimônio ficam sujeitos à arrecadação pelo Município ou pelo Distrito Federal na condição de bem vago.

$\S 1$ ㅇ A intenção referida no caput deste artigo será presumida quando o proprietário, cessados os atos de posse sobre o imóvel, não adimplir os ônus fiscais instituídos sobre a propriedade predial e territorial urbana, por cinco anos.

§ 20 O procedimento de arrecadação de imóveis urbanos abandonados obedecerá ao disposto em ato do Poder Executivo municipal ou distrital e observará, no mínimo:

I - abertura de processo administrativo para tratar da arrecadação;

II - comprovação do tempo de abandono e de inadimplência fiscal;

III - notificação ao titular do domínio para, querendo, apresentar impugnação no prazo de trinta dias, contado da data de recebimento da notificação.

$\S$ 3ำ A ausência de manifestação do titular do domínio será interpretada como concordância com a arrecadação.

$\S 4$ ㅇ Respeitado o procedimento de arrecadação, o Município poderá realizar, diretamente ou por meio de terceiros, os investimentos necessários para que o imóvel urbano arrecadado atinja prontamente os objetivos sociais a que se destina.

§ 5o Na hipótese de o proprietário reivindicar a posse do imóvel declarado abandonado, no transcorrer do triênio a que alude o art. 1.276 da Lei no 10.406, de 10 de janeiro de 2002 (Código Civil), fica assegurado ao Poder Executivo municipal ou distrital o direito ao ressarcimento prévio, e em valor atualizado, de todas as despesas em que eventualmente houver incorrido, inclusive tributárias, em razão do exercício da posse provisória.

A norma jurídica, assim, determinou aspectos gerais do procedimento mínimo a ser adotado pelos municípios e Distrito Federal, suprindo a lacuna existente na Lei Civil, quais sejam: abertura de processo administrativo para tratar da arrecadação; comprovação do tempo de abandono e de inadimplência fiscal sobre a propriedade predial e territorial urbana, por cinco anos; e notificação ao titular do domínio para, querendo, apresentar impugnação no prazo de trinta dias, contado da data de recebimento da notificação.

O procedimento pormenorizado da arrecadação, conforme estabelece a lei, ficará a cargo de "ato do Poder Executivo Municipal ou distrital", indicando a possibilidade de ser disciplinado por decreto do executivo.

A presunção absoluta de abandono do imóvel ainda foi definida a partir do marco temporal de cinco anos de inadimplência fiscal, além de ser estabelecida a necessidade de processo 
administrativo, com a notificação do titular, garantindo, assim, a existência de contraditório anteriormente à arrecadação.

Ademais, durante o procedimento de arrecadação, o §4ㅇ do Art. 64 permitiu ao município prontamente realizar as ações necessárias para que o imóvel cumpra a sua função social antes mesmo da finalização do procedimento.

Quanto ao cumprimento de tais fins sociais, a própria Lei n.o 13.465/2017 discrimina usos a que devem ser destinados os imóveis abandonados arrecadados pelo Município:

Art. 15. Poderão ser empregados, no âmbito da Reurb, sem prejuízo de outros que se apresentem adequados, os seguintes institutos jurídicos:

(...)

IV - a arrecadação de bem vago, nos termos do art. 1.276 da Lei no 10.406 , de 10 de janeiro de 2002 (Código Civil);

(...)

Art. 65. Os imóveis arrecadados pelos Municípios ou pelo Distrito Federal poderão ser destinados aos programas habitacionais, à prestação de serviços públicos, ao fomento da Reurb-S ou serão objeto de concessão de direito real de uso a entidades civis que comprovadamente tenham fins filantrópicos, assistenciais, educativos, esportivos ou outros, no interesse do Município ou do Distrito Federal.

Pela leitura dos artigos, verifica-se que a Lei priorizou que os bens vagos arrecadados pelos municípios sejam destinados para o fomento de programas habitacionais e fomento da regularização fundiária urbana de interesse social - Reurb-S, atendendo, nesse sentido, à função social da propriedade urbana e da cidade, especificamente à prestação estatal para cumprimento do direito à moradia à população mais carente ou que esteja em áreas de risco.

Outrossim, a norma em comento também priorizou a utilização desses imóveis para prestação de serviços públicos ou para concessão de direito real de uso a entidades civis que comprovadamente tenham fins filantrópicos, assistenciais, educativos, esportivos.

Embora, em princípio, verifique-se que a arrecadação de imóveis abandonados aponte para benefícios aos municípios como uma instrumento da política urbana, analisando-se os Planos Diretores das 27 capitais dos estados brasileiros, verifica-se que o instrumento não está regulamento nas legislações municipais da maioria das capitais.

Contudo esteja previsto desde 2002 no Código Civil, apenas as capitais São Paulo/SP (Lei Municipal n.o 16.050/2014) e Vitória/ES (Lei Municipal n.o 9.271/2018), na revisão de seus Planos Diretores Urbanos, estabeleceram previsão legal para tanto, nesses termos:

PLANO DIRETOR DE SÃO PAULO/SP - LEI N.o 16.050/2014

Subseção VIII Da Arrecadação de Bens Abandonados 
Art. 108. O imóvel que o proprietário abandonar, com a intenção de não mais o conservar em seu patrimônio, e que se não encontrar na posse de outrem, poderá ser arrecadado, como bem vago, e após três anos ser incorporado à propriedade do Município, conforme estabelece a legislação federal.

$\S 1$ o Poderá haver arrecadação pelo Município de imóvel abandonado quando ocorrerem as seguintes circunstâncias:

I - o imóvel encontrar-se vago, sem utilização e sem responsável pela sua manutenção, integridade, limpeza e segurança;

II - o proprietário não tiver mais a intenção de conservá-lo em seu patrimônio;

III - não estiver na posse de outrem;

IV - cessados os atos de posse, estar o proprietário inadimplente com o pagamento dos tributos municipais incidentes sobre a propriedade imóvel.

§ 2ㅇ A Prefeitura deverá adotar as providências cabíveis à incorporação definitiva do bem abandonado ao patrimônio público, nos termos estabelecidos pelo regulamento, cabendo ao Poder Executivo:

I - tomar as medidas administrativas necessárias para a arrecadação dos bens abandonados, observando-se desde o início o direito ao contraditório e à ampla defesa;

II - adotar as medidas judiciais cabíveis para regularização do imóvel arrecadado junto ao Serviço Registrário Imobiliário, bem como para sua destinação às finalidades previstas nesta lei.

Art. 109. O imóvel que passar à propriedade do Município em razão de abandono poderá ser empregado diretamente pela Administração, para programas de habitações de interesse social, de regularização fundiária, instalação de equipamentos públicos sociais ou de quaisquer outras finalidades urbanísticas.

Parágrafo único. Não sendo possível a destinação indicada no artigo anterior em razão das características do imóvel ou por inviabilidade econômica e financeira, o bem deverá ser alienado e o valor arrecadado será destinado ao Fundo Municipal de Habitação para a aquisição de terrenos e glebas.

Art. 110. O procedimento para arrecadação terá início de ofício ou mediante denúncia, que informará a localização do imóvel em cujos atos de posse tenham cessado.

§ 10 Para dar seguimento ao procedimento de arrecadação, a Prefeitura deverá: I - abrir processo administrativo que deverá conter os seguintes documentos:

a) requerimento ou denúncia que motivou a diligência;

b) certidão imobiliária atualizada;

c) certidão positiva de existência de ônus fiscais municipais;

d) outras provas do estado de abandono do imóvel, quando houver;

e) cópias de ao menos 3 (três) notificações encaminhadas ao endereço do imóvel ou àquele constante da matrícula ou transcrição imobiliária; II - realizar atos de diligência, mediante elaboração de relatório circunstanciado contendo a descrição das condições do imóvel;

III - confirmar a situação de abandono, com a lavratura do respectivo Auto de Infração e a instrução de processo administrativo.

PLANO DIRETOR DE VITÓRIA/ES - LEI n. 9.271/2018

Capítulo X Da arrecadação de imóvel abandonado

Art. 271. O imóvel urbano que o proprietário abandonar, com intenção de não mais o conservar em seu patrimônio, e que não se encontrar na posse de 
outrem, poderá ser arrecadado como bem vago e passar, três anos depois, à propriedade do Município.

$\S 1$ 1․ No caso de qualquer imóvel se encontrar na situação descrita no caput, o Poder Público Municipal poderá instaurar processo administrativo em que será assegurado contraditório e ampla defesa para arrecadação do imóvel abandonado de conformidade com o disposto em regulamento.

$\S$ 2‥ Para fundamentar a edição do Decreto de arrecadação de imóvel abandonado, presumir-se-á de modo absoluto a intenção a que se refere este artigo quando, cessados os atos da posse, deixar o proprietário de satisfazer os ônus fiscais.

§ 3‥ O prazo de três anos previstos neste artigo começa a contar da publicação do Decreto de arrecadação.

Art. 272. O Decreto de arrecadação do imóvel abandonado autoriza o Município tomar posse do imóvel e promover reformas e benfeitorias.

Art. 273. Caso o proprietário, durante o prazo de três anos, manifeste seu interesse na conservação do imóvel, o Município terá direito de retenção do bem enquanto não for indenizado pelo dobro do valor das benfeitorias realizadas.

Art. 274. Serão preferencialmente arrecadados os imóveis situados na Macrozona Urbana de Reestruturação e nas ZEIS.

Parágrafo único. Quando arrecadados imóveis situados em ZEIS, estes deverão ser utilizados para regularização fundiária de interesse social e implantação de EHIS.

Verifica-se que ambas as leis repetiram o lapso temporal de três anos, após a declaração de bem vago, para incorporação do imóvel ao patrimônio municipal. O referido prazo é o mesmo estatuído pelo art. 1.276 do Código Civil.

Ambas também adotam como prioridade a destinação dos bens vagos a habitação de interesse social e à regularização fundiária, de modo que o cumprimento do direito à moradia foi elencado como prioritário para ambas as capitais. Acresce o município de São Paulo a destinação também para instalação de equipamentos públicos sociais, preponderando, nesse município, a destinação para fins de interesse social, conforme definição existente no art. 20 da Lei 4.132/1962.

No procedimento estabelecido no Plano Diretor de Vitória/ES, no art. 272, à semelhança do procedimento adotado para desapropriação de utilidade pública (Decreto-Lei № 3365/1941), foi prevista a publicação de Decreto municipal declarando a arrecadação do imóvel, sendo o marco inicial para contagem do lapso de três anos para a consumação da vacância do bem e integração e incorporação ao patrimônio público municipal.

A publicação de Decreto do Executivo, descrevendo detalhadamente o bem, cumpre com o princípio da publicidade e fornece segurança jurídica aos próximos passos até à incorporação ao patrimônio municipal ou distrital, particularmente se for a intenção do proprietário contestar a medida e reaver o seu bem, e assim dar destinação adequada aos fins urbanos a este. 
Ressalte-se que o Plano Diretor de Vitória/ES é um dos primeiros, dentre as capitais brasileiras, a ter passado por um processo de revisão após a publicação da Lei Federal no 13.465/2017, que deu as diretrizes procedimentais para a arrecadação de imóveis abandonados.

Ainda, verificou-se que após a publicação do Plano Diretor Urbano de São Paulo, outros grandes municípios paulistas procederam com a revisão dos seus planos diretores, incorporando nestes o instrumento de arrecadação de imóveis abandonados, alguns com dispositivos bastante semelhantes aos da capital, a exemplo dos municípios de Santos/SP (Lei Complementar n.o 1005/2018) e outros apenas prevendo-o como instrumento da política urbana, como Campinas/SP (Lei Complementar n.ㅇ 189/2018)

Nesse cenário, espera-se que, à medida que os demais municípios realizem a revisão dos seus planos diretores urbanos, a arrecadação de imóveis abandonados esteja presente nas legislações municipais como um dos instrumentos da política urbana, nos termos já definidos pelo Estatuto da Cidade para o parcelamento, edificação ou utilização compulsórios, IPTU progressivo no tempo e desapropriação com pagamento de títulos.

E não apenas como um instrumento com vaga previsão da possibilidade de ser utilizado, sem regras específicas que norteiem o Executivo na efetiva implantação do instrumento, mas com a devida regulamentação do procedimento a ser adotado pelos municípios, direcionando políticas públicas para tanto.

A incorporação e disciplina normativa da arrecadação de imóveis abandonados como instrumento da política urbana vem agregar aos instrumentos já previstos no Estatuto da Cidade, com fins de combater a perpetuação de imóveis subutilizados e não utilizados em áreas urbanas e a especulação imobiliária em áreas com infraestrutura urbana já implantada.

Assim, a depender da característica do imóvel, tais como tempo de abandono, estado de manutenção, tipologia, área e localização, a Administração Pública poderá aferir qual o melhor instrumento a ser aplicado para atingir fins de interesse público e social, se por adoção de medidas coercitivas para que o próprio proprietário dê uma função social ao seu imóvel (parcelamento, edificação ou utilização compulsórios e IPTU progressivo no tempo), ou pela adoção de medidas drásticas, com a perda da propriedade para a Administração Pública, que deverá fazer cumprir, por sua iniciativa, tal função social da propriedade.

\section{A APROPRIAÇÃO DE IMÓVEIS ABANDONADOS COMO INSTRUMENTO PARA EFICIÊNCIA MUNICIPAL}


A Administração Pública, nos termos do art. 37 da Constituição Federal de 1988, em todas as suas esferas, deverá obedecer ao princípio da eficiência administrativa.

Em termos práticos, cumpre-se com a "eficiência quando a ação administrativa atinge materialmente os seus fins lícitos, e por vias lícitas. Quando o administrado se sente amparado e satisfeito na resolução dos problemas que initerruptamente leva à Administração" (FRANÇA, 2000).

Ademais, o princípio da eficiência abrange ainda um viés econômico no uso de recursos públicos:

(...) primando pela adoção dos critérios legais e morais necessários para melhor utilização possível dos recursos públicos, de maneira a evitar-se desperdícios e garantir-se uma maior rentabilidade social. Note-se que não se trata da consagração da tecnocracia, muito pelo contrário, o princípio da eficiência dirige-se para a razão e fim maior do Estado, a prestação dos serviços públicos sociais essenciais à população, visando a adoção de todos os meios legais e morais possíveis para a satisfação do bem comum" (MORAIS, 2018).

Nesse sentido, a apropriação de imóveis abandonados serve à prestação estatal para cumprimento do direito à moradia à população vulnerável e/ou hipossuficiente, o que poderia diminuir os custos estatais diretos com a construção de novas casas populares, desapropriações, abrigos e aluguel social.

Ainda, considerando-se que os altos custos de imóveis urbanos nas áreas centrais da cidade deslocam a população, especialmente de baixa renda, para áreas periféricas, carentes de infraestrutura urbana, a ocupação de tais imóveis reduziria a expansão da mancha urbana e, consequentemente, retardaria a necessidade de investimentos para expansão das redes de água, esgotamento sanitário e mobilidade urbana, como exemplos.

Outrossim, a arrecadação de imóveis abandonados poderia ser instrumento alternativo ao direito de preempção, instrumento que "confere ao Poder Público municipal preferência para aquisição de imóvel urbano objeto de alienação onerosa entre particulares" (art. 25 do Estatuto da Cidade), podendo ser usado, dentre outros, para criação de espaços públicos de lazer e áreas verdes e proteção de áreas de interesse histórico e cultural. Desse modo, nas áreas delimitadas pelo município para incidência do direito de preempção, os bens abandonados ali identificados poderiam ser arrecadados pelo Município, sem o ônus financeiro presente no primeiro, e destinados aos fins pretendidos para a área.

Sob esse aspecto, o instrumento de arrecadação de bens abandonados torna-se especialmente atraente, tendo em vista que em muitos municípios brasileiros, a exemplo de Natal/RN, o centro histórico é pouco habitado por moradores, constituindo-se de grande número de imóveis sem destinação, muitas vezes abandonados por herdeiros. Assim, incorporados ao patrimônio municipal, estes imóveis poderiam ser utilizados pelo poder público para requalificação 
dessas áreas, com novos usos, dinamizando a cidade, em áreas bem localizadas e que já gozam de infraestrutura urbana.

No que tange à utilização de bens abandonados para prestação de serviços públicos, os municípios, muitas vezes, em razão da escassez de imóveis públicos suficientes para atendimento às demandas da população, necessitam locar imóveis particulares para instalação de órgãos públicos que estejam nas proximidades onde habitam seus usuários, como secretarias municipais, unidades básicas de saúde, escolas e centros de referência de assistência social. Desse modo, a depender das características dos imóveis abandonados arrecadados, a destinação destes para tais fins poderia reduzir os custos com locação com imóveis pelo poder público.

Não se pode deixar de mencionar que a previsão legal, especialmente quando incorporada à legislação urbanística municipal, de declaração de vacância do imóvel tido como abandonado, com a possibilidade de perda da propriedade, tendo como prova presumida o inadimplemento do IPTU por cinco anos, poderia coagir os proprietários de imóveis que não queiram sofrer tal sanção a quitar os débitos fiscais junto ao município, bem como realizar a limpeza e manutenção do seu patrimônio, o que diminuiria a inadimplência do imposto, bem como reduziria custos na fiscalização ambiental e urbanística para averiguar o mau estado de conservação e a propagação de vetores de doenças nesses imóveis, que causam danos e riscos à vizinhança.

A arrecadação de tais imóveis como bens vagos, sendo uma de suas características a existência de débitos fiscais por 5 anos ou mais, seria uma medida para reduzir ônus fiscal, ambiental, urbanístico e imobiliário destes imóveis, ao compensar o IPTU devido com a utilização compulsória para fins de interesse público ou social, diminuindo o custo estatal nessas áreas.

Sob essa perspectiva, a utilização compulsória desses imóveis para fins públicos e para atendimento a demandas sociais cumpriria também o princípio da eficiência no uso dos recursos para as despesas e receitas públicas pela Administração Pública, com economia de recursos públicos, e, especialmente, promovendo a destinação social de bens que, até então, representavam um problema urbano.

\section{CONCLUSÃO}

Ante o exposto, verifica-se que a disciplina legal da arrecadação de imóveis abandonados por parte do poder público municipal atende aos fins da função social da propriedade privada, particularmente da urbana, e da cidade, ao exigir que o bem imóvel que não atenda a uma função útil tenha uma finalidade coletiva, visando, primordialmente, à garantia ao direito à moradia e minimizando o déficit habitacional dos grandes centros urbanos brasileiros. 
Ainda que seja um instrumento com previsão desde o Código Civil de 1916, com nova disciplina no Código Civil de 2002, a arrecadação de imóveis abandonados pouco foi incorporada à legislação municipal dos municípios brasileiros e menos ainda regulamentada (o Plano Diretor de São Paulo/SP e o Plano Diretor de Vitória/ES definiram regras para o procedimento apenas em 2014 e 2018, respectivamente) por aqueles que estatuíram algum tipo de previsão em leis locais. A Lei Federal de n.o 13.465/2017 disciplinou regras gerais para estabelecer o procedimento mínimo a ser adotado pelos municípios brasileiros, que certamente auxiliará o ente federativo a traçar suas próprias normas, conforme a realidade local.

A adoção de políticas públicas utilizando-se a previsão legal nos municípios que regulamentaram ainda se mostra muito incipiente e pontual e, muitas vezes, a ocupação dos imóveis abandonados se dá à revelia do Poder Público, mas por iniciativa de movimentos populares, o que requer cautela, particularmente pelo mau estado que muitos prédios se encontram.

A intervenção do Estado na propriedade privada no uso do instrumento da arrecadação de imóveis abandonados mostra-se como medida de eficiência administrativa, cumprindo a exigência constitucional de atendimento à função social da cidade e da propriedade, com a sobreposição de interesses coletivos e públicos acima dos individuais, pelo próprio não exercício, nos termos legais, do direito individual positivado. $O$ ente federativo municipal passa, então, a titularizar os interesses públicos, impedindo o não-uso da propriedade, especialmente quando esta se torna um ônus à coletividade, com ameaças à segurança e à salubridade públicas.

A apropriação de tais imóveis seria uma das formas de economia de recursos públicos, ao destinar tais imóveis para famílias desprovidas de moradia própria, e que dependem do benefício assistencial eventual do aluguel social ou auxílio moradia. Outra forma seria destinação para instalação de órgãos públicos para prestação de serviços públicos, como de saúde, educação e assistência social, dentre outros, diminuindo custos com a locação de imóveis privados.

Sob esse espectro, a utilização do instrumento de arrecadação de imóveis abandonados pelos Municípios teria natureza vinculada, especialmente se pensada pelo viés da eficiência administrativa e economia de recursos públicos, diretamente, com a redução de despesas públicas, e indiretamente, já que imóveis abandonados geram ônus em diferentes gargalos municipais, a exemplo da segurança pública, saúde, meio ambiente e urbanismo e defesa civil.

\section{REFERÊNCIAS}

BORGES, R. C. B. Função ambiental da propriedade. Revista de Direito Ambiental, v. 9, p. 67-85, jan./mar, 1998. 
BRASIL. Constituição da República Federativa do Brasil de 1988. Disponível em:

<http://www.planalto.gov.br/ccivil_03/constituicao/constituicao.htm> Acesso em: 24 jan. 2020.

BRASIL. Lei № 10.257, de 10 de julho de 2001. Regulamenta os arts. 182 e 183 da Constituição Federal, estabelece diretrizes gerais da política urbana e dá outras providências. Disponível em: <http://www.planalto.gov.br/ccivil_03/constituicao/constituicao.htm> Acesso em: 25 jan. 2020.

BRASIL. Lei № 10.406, de 10 de janeiro de 2002. Institui o Código Civil. Disponível em: <http://www.planalto.gov.br/ccivil_03/leis/2002/L10406.htm>. Acesso em: 22 jan. 2020.

BRASIL. Lei № 13.465, de 11 de julho de 2017. Dispõe sobre a regularização fundiária rural e urbana. Disponível em: <http://www.planalto.gov.br/ccivil_03/_Ato2015-2018/2017/Lei/L13465.htm>. Acesso em: 22 jan. 2020.

CAMPOS, J. R. Direito de propriedade sobre as águas e o registro de imóveis. Revista de Direito Imobiliário, v. 51, p. 203, jul, 2001. Disponível em: <https://www.irib.org.br/publicacoes/rdi/rdiedicao-51> Acesso em: 6 jul. 2020.

CARTA de Atenas, de novembro de 1933. Assembleia do CIAM - Congresso Internacional de Arquitetura Moderna, item 77. Disponível em:

<http://www.iphan.gov.brflegislac/cartaspatrimoniais/atenas>. Acesso em 4 jul. 2020.

CARVALHO FILHO, J. S. Comentários ao Estatuto da Cidade. 3. ed. Rio de Janeiro: Lumen Juris, 2009.

DÉFICIT habitacional no Brasil 2015. Fundação João Pinheiro, Diretoria de Estatística e Informações. Belo Horizonte: FJP, 2018. 78 p. (Estatística \& Informações; n. 6). Disponível em:

$<$ http://www.bibliotecadigital.mg.gov.br/consulta/consultaDetalheDocumento.php?iCodDocumento $=76871>$. Acesso em 5 jul. 2020.

DIMOULIS, D; MARTINS, L. Teoria Geral dos Direitos Fundamentais. 4. ed. Atlas, 2012.

FIUZA, C. Direito civil: Curso completo. 6. ed. Belo Horizonte: Del Rey, 2003.

FRANÇA, V. R. Eficiência administrativa na Constituição Federal. Revista de Direito Administrativo. Rio de Janeiro, v. 220, p. 165-177, abr. 2000. Disponível em: <

http://bibliotecadigital.fgv.br/ojs/index.php/rda/article/view/47532> Acesso em 6 jul. 2020.

GAIO, D. A propriedade urbana e o direito de edificar. Revista de Direito Ambiental, v. 20, p. 121158, out, 2000.

GONÇALVES, C. R. Direito civil brasileiro, volume 5: Direito das coisas. 12. ed. São Paulo: Saraiva, 2017.

MORAIS, A. de. Direito Constitucional. 34 ed. São Paulo: Atlas, 2018.

PEREIRA, C. M. S. Instituições de direito civil - Vol IV. 25. ed. Rio de Janeiro: Forense, 2017.

REBOUÇAS, R. F. O bem comum e a função social da propriedade. Revista de Direito Privado, v. 47, p. 311-330, jul, 2011. 
RODRIGUES, D. R. Função social da propriedade privada diante do meio ambiente artificial. Revista de Direito Imobiliário, v. 70, p. 83-171, jan./jun, 2011.

SÃO PAULO. Lei № 16.050, de 31 de julho de 2014. Aprova a Política de Desenvolvimento Urbano e o Plano Diretor Estratégico do Município de São Paulo e revoga a Lei no 13.430/2002. Disponível em: < https://gestaourbana.prefeitura.sp.gov.br/arquivos/PDE_lei_final_aprovada/TEXTO/2014-0731\%20-\%20LEI\%2016050\%20-\%20PLANO\%20DIRETOR\%20ESTRAT\%C3\%89GICO.pdf> Acesso em 5 jul. 2020.

SINOPSE do Censo Demográfico 2010. Rio de Janeiro: IBGE, 2011. Disponível em: <https://censo2010.ibge.gov.br/sinopse/index.php?dados=16\&uf=00> Acesso em: 6 jul. 2020.

SÍNTESE de indicadores sociais 2019: uma análise das condições de vida da população brasileira. Rio de Janeiro: IBGE, 2019. 130 p. (Estudos e pesquisas. Informação demográfica e socioeconômica, ISSN 1516-3296; n. 40). Disponível em: <https://biblioteca.ibge.gov.br/visualizacao/livros/liv101678.pdf>. Acesso em: 5 jul. 2020.

SILVA, J. A. Direito Urbanístico Brasileiro. 6. ed. São Paulo: Malheiros, 2010.

VITÓRIA. Lei № 9.271, de 22 de maio de 2018. Aprova o Plano Diretor Urbano do Município de Vitória e dá outras providências. Disponível em:

<http://sistemas.vitoria.es.gov.br/webleis/Arquivos/2018/L9271.PDF>. Acesso em: 20 jan. 2020.

TARTUCE, F. Manual de Direito Civil. 10. ed. São Paulo: Método, 2020.

Trabalho enviado em 16 de julho de 2020

Aceito em 23 de setembro de 2021 